\title{
A sereiazinha: Conto original e adaptações, uma análise crítica.
}

\author{
Diogo Fernando dos Santos ${ }^{1}$ \\ Universidade de Taubaté
}

\begin{abstract}
Resumo
Este trabalho tem como objetivo fazer um levantamento das semelhanças e das diferenças entre o conto de fadas original $A$ sereiazinha, escrito por Hans Christian Andersen, e outras três adaptações, a fim de se estabelecer critérios que definam a qualidade textual. Para análise dos dados, procedeu-se a uma descrição bibliográfica e à análise qualitativa das informações teóricas, buscando verificar os elementos que teriam mudado entre uma obra original e suas adaptações. Para tanto, foram organizados quadros explicativos, os quais se dividem em: enredo, narração, caracterização do personagem principal e descrição de cenários. A pesquisa se fundamentou nas contribuições teóricas de Coelho $(1987,2000,2003)$ e Propp (2001) entre outras. Os resultados mostraram que os detalhes descritos no texto original contribuem para uma melhor compreensão da história. Pôde-se concluir que o texto original oferece uma riqueza de detalhamentos, propiciando uma melhor compreensão mais crítica e reflexiva sobre a história.
\end{abstract}

Palavras-chave: Leitura. Conto de fadas. Análise qualitativa.

\begin{abstract}
:
This work aims to make a survey of the similarities and differences between the original fairy tale The Little Mermaid, written by Hans Christian Andersen, and three other adaptations, in order to establish criteria that define the textual quality. To analyze the data, a bibliographic description and a qualitative analysis of the theoretical information were used in order to verify the elements that would have changed between an original work and its adaptations. Therefore, explanatory tables were sorted into: plot, narration, characterization of the main character and description of scenarios. The research was based on the theoretical contributions of Coelho (1987, 2000, 2003) and Propp (2001) among others. The results showed that the details described in the original text contribute to a better understanding of the story. To sum up, the original text offers a wealth of details, providing a better critical and reflective understanding of the story.
\end{abstract}

Keywords: Reading. Fairy tale. Qualitative analysis.

\section{INTRODUÇÃO}

A literatura, em particular os contos de fadas, tornou-se um instrumento didático relevante para o ensino, já que, de acordo com Coelho (2003), tem um importante papel na formação das novas gerações. Vivemos numa era de transformações ocorridas em todos os setores da sociedade. A Educação e o Ensino também foram afetados com as mudanças de

\footnotetext{
${ }^{1}$ Mestrando em Linguística Aplicada pela Universidade de Taubaté. Orientadora Prof ${ }^{\mathrm{a}} \mathrm{Dr}^{\mathrm{a}}$ Maria José Milharezi Abud.
} 
paradigma e de visão de mundo novo, assim afirma a autora, e é justamente por meio da literatura que se busca conscientizar esse novo homem:

\begin{abstract}
Aí está o valor substancial da literatura como criação: sua matéria prima é a existência humana e o seu meio transmissor é a palavra, a linguagem - exatamente o meio do qual tudo no mundo necessita para ser nomeado e existir verdadeiramente para todos os homens (COELHO, 2003, p. 87).
\end{abstract}

Acreditamos que os contos de fadas devem ser trabalhados pelo professor nos anos iniciais do Ensino Básico, porque, de acordo com Bettelheim (2007, p. 34), eles, “[...] diferentemente de qualquer outra forma de literatura, direcionam a criança para a descoberta de sua identidade e vocação, e também sugerem as experiências que são necessárias para desenvolver ainda mais o seu caráter". Esta afirmação faz com que o autor defenda uma literatura infantil que contribua com o intelecto das crianças, que deslinde a imaginação e que torne os sentimentos e emoções mais visíveis; e que, com isso, as crianças consigam falar sobre suas aflições, anseios e aspirações para vida. Nos contos de fadas há manifestação de formas inspiradoras, ricas em seu conteúdo.

A importância da literatura, especificamente dos contos de fadas no universo infantil, se dá pelo fato de que há uma sintonia entre o atual e o arcaico, pois:

[...] de maneira lúdica, fácil e subliminar, ela atua sobre os pequenos leitores, levando-os a perceber e a interrogar a si mesmos e ao mundo que os rodeia, orientando seus interesses, suas aspirações, sua necessidade de autoafirmação, ao lhes propor objetivos, ideias ou formas possíveis (ou desejáveis) de participação no mundo que os rodeia. (COELHO, 2003, p. 92).

No entanto, a leitura dos contos de fadas em sala de aula envolve duas questões: ler uma obra original ou uma obra adaptada? Quais critérios elencar para escolher entre uma e outra?

Percebemos que certas adaptações parecem possuir menos qualidades que outras. De acordo com os Parâmetros Curriculares de Língua Portuguesa - doravante PCN - (BRASIL, 2000), se a escola tem como objetivo formar cidadãos proficientes na leitura, então, é preciso lhes oferecer bons modelos para isso. A escolha do livro, portanto, que será trabalhado pelo professor, contribuirá, como afirmam os PCN (BRASIL, 2000), no processo educativo dos alunos, permitindo a eles experimentarem e aprenderem com um material de boa qualidade.

Assim, escolhemos uma obra escrita por Hans Christian Andersen - A sereiazinha e outras três adaptações feitas, para elucidar nossa pesquisa. Como objetivo visamos a estabelecer critérios para se fazer um levantamento das semelhanças e das diferenças entre o 
texto original e as três adaptações escolhidas. O resultado obtido nessa pesquisa é relevante porque pode fornecer subsídios para que o professor consiga se nortear nas escolhas de textos para serem trabalhados em sala de aula.

Metodologicamente, procedemos à pesquisa bibliográfica e à análise qualitativa das informações teóricas, buscando verificar os elementos que teriam mudado entre uma obra original e suas adaptações. Apresentamos, para tanto, quadro explicativos, os quais se dividem em: narração; caracterização do personagem principal; descrição de cenários e enredo. Assim, buscamos uma fundamentação em Coelho (1987, 2000, 2003) e Propp (2001).

Essa pesquisa se divide em duas seções. Na primeira, apresentamos um resumo do conto A sereiazinha, explicando porque se trata de um conto de fadas e não um conto maravilhoso. Na segunda Seção, e com base estabelecidas por Propp (2001) e Coelho (2000), efetuamos as comparações de semelhanças e diferenças existentes nas adaptações, evidenciando o enredo, o narrador, a personagem principal e o cenário. Desse modo, com base nessa comparação, estabelecemos um quadro de critérios que especifique a qualidade de uma produção escrita. Segue a conclusão.

\section{ANDERSEN E SEU CONTO: A SEREIAZINHA}

Hans Christian Andersen, escritor dinamarquês, do início do século XIX, é considerado, de acordo com Ash e Higton $(1995)^{2}$, um escritor que trouxe inovação em seus escritos ao usar uma linguagem do cotidiano, “[...] o que explica a estrutura frequentemente incomum dos contos e o uso de frases curtas, fragmentadas" (p. 8). Lajolo e Zilberman (2007) dissertam que o século XIX foi o prelúdio para a expansão bem-sucedida da literatura infantil. Começou com os irmãos Grimm, em 1822, que, após obterem êxito na edição dos contos de fadas escritos, começaram a prestar mais atenção nos tipos de livros que agradariam as crianças e perceberam que essas narrativas eram algo que chamava a atenção desse público; o mesmo ocorreu com Andersen, que tomou esse mesmo cuidado para escrever suas histórias. Coelho $(1987,2000)$ esclarece que, na era de Andersen, os contos de fadas já tinham tomado características de narrativas cristãs e traziam valores básicos de visão de mundo. Dessa forma, a autora elucida sobre três representações de mundo acerca dessas narrativas folclóricas:

1. A do mundo real, cotidiano, nos primórdios da história, quando imperava a força bruta ou o direito do mais forte e, cujos vícios e virtudes eram representados nas narrativas através do simbolismo animal que deu nascimento às fábulas.

\footnotetext{
${ }^{2}$ Autores que compilaram o livro Histórias maravilhosas de Andersen, da editora Companhia das Letrinhas.
} 
2. A do mundo das metamorfoses, resultantes da fusão do mundo real e do transreal ou espiritual, representados nas narrativas por uma realidade mágica. É este o mundo dos contos de fadas ou contos maravilhosos em geral, povoados por personagens que representam, simbolicamente, valores e estruturas sociais arcaicas.

3 ....] A do mundo religioso cristão, no qual a vida terrena é vista como passagem para o céu ou para o inferno; é o 'vale de lágrimas' onde o 'homem da queda' deve pagar sua culpa... Daí a valorização das narrativas exemplares, em que a Virtude é exaltada e o Vício ou Pecado, condenados. (COELHO, 2000, p. 95, grifo da autora).

Nos textos de Andersen, segundo Coelho (2000), várias histórias foram inventadas pelo escritor, ou retiradas do folclore dinamarquês, sempre circundadas por um ideárioromântico-cristão.

[...] são exemplares como transfiguração literária daquela orientação ético-religiosa. Muitas de suas histórias realistas: situam-se no mundo real, cotidiano, com personagens simplesmente humanas em luta com as adversidades da vida e, em geral, vencidos por elas, mas vitoriosos na conquista do céu.

[...] Nota-se, no geral das narrativas de Andersen, a tendência para fundir o maravilhoso pagão com o espiritualismo cristão. (COELHO, 2000, p. 95-96).

No conto A sereiazinha é perceptível o que foi descrito pela autora. Segue abaixo o resumo da história, para uma melhor compreensão do assunto:

Uma sereiazinha ao completar seus quinze anos, ganhou de presente o direito de ir à superfície apreciar o mundo dos humanos. Curiosa e diferente das outras irmãs, desde pequena esperou impacientemente por esse dia. Quando isso aconteceu, encontrou na superfície um navio com pessoas festejando o aniversário de um jovem rapaz, cuja beleza a encantou. Entretanto, a noite não seria apenas de alegria, uma forte tempestade fez com que o navio naufragasse. Decidida a não deixar o príncipe morrer, salvou-o, levando-o até uma baía de águas calmas, rodeada por uma praia de areia branca. No entanto, ele nem pôde agradecer-lhe, pois estava desacordado; quando despertou, viu uma jovem moça e, em seguida, suas amigas que pertenciam a um templo religioso.

Esse ato mudou a vida da pobre sereiazinha. Meses se passaram e a jovem sereia não conseguiu esquecer o príncipe, apaixonou-se por ele e o desejo de saber tudo sobre os humanos aumentou. Como aumentou sua angustia, quando descobriu que sereias não tinham direito à imortalidade da alma, algo apenas reservado aos humanos, e o que lhes restava após a morte era se tornar espumas do mar. Decidida a reencontrar o rapaz e ter a chance de ter imortalidade, procurou a bruxa do mar, que lhe propôs um acordo: que ela receberia a forma humana, em troca de sua linda voz. Sobre a imortalidade, só conseguiria, caso conseguisse o amor do jovem príncipe e se cassasse com ele, caso contrário, morreria.

A sereia tomou da poção feita, e o que tanto desejou se transformou em realidade. Reencontrou o jovem rapaz, que também se sentiu atraído pela jovem desconhecida que não falava, mas dançava lindamente. Passou a querê-la bem, amou como se ama uma criança, mas não desejou tê-la como rainha. Seu coração estava guardado a uma jovem garota, a quem achava que o havia salvado do naufrágio. Meses depois, o príncipe anunciou à sereiazinha que os pais tinham intenção de casá-lo; mesmo a contragosto, aceitou o compromisso e, quando encontrou com sua futura esposa, descobriu que se tratava da jovem moça que o 
salvara do naufrágio, assim acreditava. Quando a sereiazinha soube disso, uma tristeza profunda a tomou, pois sabia que em breve morreria. As outras sereias, decididas a ajudar a irmã, fizeram um acordo com a bruxa e doaram seus cabelos em troca da vida da sereiazinha, que voltaria para o lar junto dos seus. A única tarefa que teria que fazer era cravar uma faca no peito do príncipe, o que se recusou e, por amor, se lançou ao mar, virando espuma. No momento da transição de sereia a espuma, os filhos do ar vieram em seu auxilio e, como a jovem sereia havia sofrido e sido resiliente, praticando boas ações, nada mais justo que lhe fosse concedida a imortalidade da alma.

\section{Conto de fadas ou conto maravilhoso?}

Em poucas palavras, resumiríamos as características que envolvem o conto $-A$ sereiazinha. No entanto, compete-nos esclarecer, com certa minúcia, o que de fato distingue contos de fadas dos contos maravilhosos. A necessidade de entender o universo dos contos de fadas tem como uma das razões compreender o próprio homem. Segundo Coelho (2003), o estudo sobre esse acervo narrativo trouxe luz ao mundo intelectual necessitando fundamentálo cientificamente. Isso se deu porque, desde meados do século XVIII, entende-se que essas narrativas, no início, contadas oralmente, trariam respostas relevantes para se compreender o comportamento. De acordo com a autora, esses contos narrados não eram somente simples ato de entretenimento.

\footnotetext{
[...] eram valiosos meios transmissores dos valores de base dos grupos sociais, valores que eram transmitidos de geração em geração, consolidando-se, assim, o Sistema de comportamentos consagrados pelo grupo. [...] A partir dessa descoberta, impôs-se ao mundo intelectual a necessidade do estudo cientifico desse acervo para lançar novas luzes na história da humanidade. (COELHO, 2003, p. 99).
}

A busca por uma classificação entre o conto maravilhoso e o simples conto popular foi discutida por vários estudiosos sobre o assunto. Destacamos Propp (2001), que criou uma morfologia - descrição - sobre os contos maravilhosos. O primeiro passo que tomou para diferi-los foi por meio de uma classificação fixa que levaria à análise de uma descrição cientifica. Essa classificação, segundo Coelho (2003, p. 10), estaria relacionada “[...] às ações dos personagens, e nelas se fundamenta para definir a especificidade do conto popular maravilhoso como gênero. E por essa via tenta chegar à possível explicação histórica de sua uniformidade em todas as regiões do mundo". Em sua pesquisa, Propp (2001) percebeu que, dos 449 contos maravilhosos estudados, havia uma construção singular entre as histórias, por isso, partiu dessa premissa para estudá-las e transformá-las num sistema de indícios formais e estruturais, da mesma forma como ocorre nas demais ciências. 
Segundo Coelho (2003, p. 110), Propp “[...] empenha-se em caracterizar os elementos que responderiam pela natureza do maravilhoso. O elemento-chave dessa caracterização, para ele, é a ação das personagens, definindo as ações como funções que estruturam a narrativa"3. Propp (2001) conseguiu chegar a uma conclusão: que as mudanças que ocorrem em determinados textos analisados estão nos nomes dos personagens, porém suas ações ou funções seriam as mesmas desempenhadas nas narrativas, cujo papel é estruturante. "Daí a conclusão de que o conto maravilhoso atribui frequentemente ações iguais a personagens diferentes. Isto nos permite estudar os contos a partir das funções dos personagens" (PROPP, 2001, p. 16). A partir disso, começou a se questionar quais funções incorporariam um conto maravilhoso. Seus questionamentos e observações sobre as funções desempenhadas pelos personagens o fizeram perceber que havia funções constantes, que, de acordo com Coelho (2003, p. 110), "são ações básicas de efabulação que identificam os contos como maravilhosos" das funções variáveis que "seriam secundárias no universo estrutural do conto". Ou seja, "as invariantes é a ordem e a consequente partida vinculada a uma busca. As variantes são os agentes da ordem, os sujeitos da partida e da busca, e também os objetos da busca" (COELHO, 2003, p. 111).

Coelho (2000) utiliza dessa organização estruturada por Propp - invariantes e variantes dos contos maravilhosos - para exemplificar o seu trabalho, porém a autora utiliza apenas cinco das 31 funções estruturadas pelo pesquisador, as mesmas que usaremos para exemplificar o conto da sereiazinha. Estas invariantes são: Desígnio, viagem, obstáculos, mediação auxiliar e conquista do objetivo ${ }^{4}$; isso se amalgama em incontáveis variantes que condizem à riqueza desses contos. É preciso esclarecer também, segundo a autora, que esses contos são oriundos das tradições populares, que passaram de narrativas orais à literatura infantil, tornando-se em obras clássicas do gênero. E justamente o que se buscou conservar do oral para o escrito foram as características genuínas desse gênero.

Construímos um esquema com base nos estudos de Coelho (1987), (2000) para esclarecer o que de fato constituem as características estilísticas e estruturais desse gênero e,

\footnotetext{
${ }^{3}$ É certo que outros estudiosos se debruçaram a entender os contos de fadas; Coelho (2003) comenta que Propp tomou das pesquisas de classificação feitas por Aarne, que diferencia quais seriam os maravilhosos dos outros contos populares.

${ }^{4}$ Segundo a autora (2000, p. 110), o desígnio está relacionado a um motivo que levou o personagem a uma ação. Já a viagem seria um deslocamento para local desconhecido pelo personagem. O obstáculo está vinculado aos empecilhos que vão surgindo de encontro às ações do personagem. O mediador seria um "auxiliar mágico, natural ou sobrenatural, que afasta ou neutraliza os perigos e ajuda o herói a vencer." Por fim, a conquista é quando o personagem realizou todas as proezas necessárias e atinge o seu objetivo.
} 
assim, podermos estabelecer a diferença entre o conto de fadas e o conto maravilhoso, e, em seguida, fazermos um quadro das invariantes do conto $A$ Sereiazinha.

\section{Esquema 1: Estrutura comparativa}

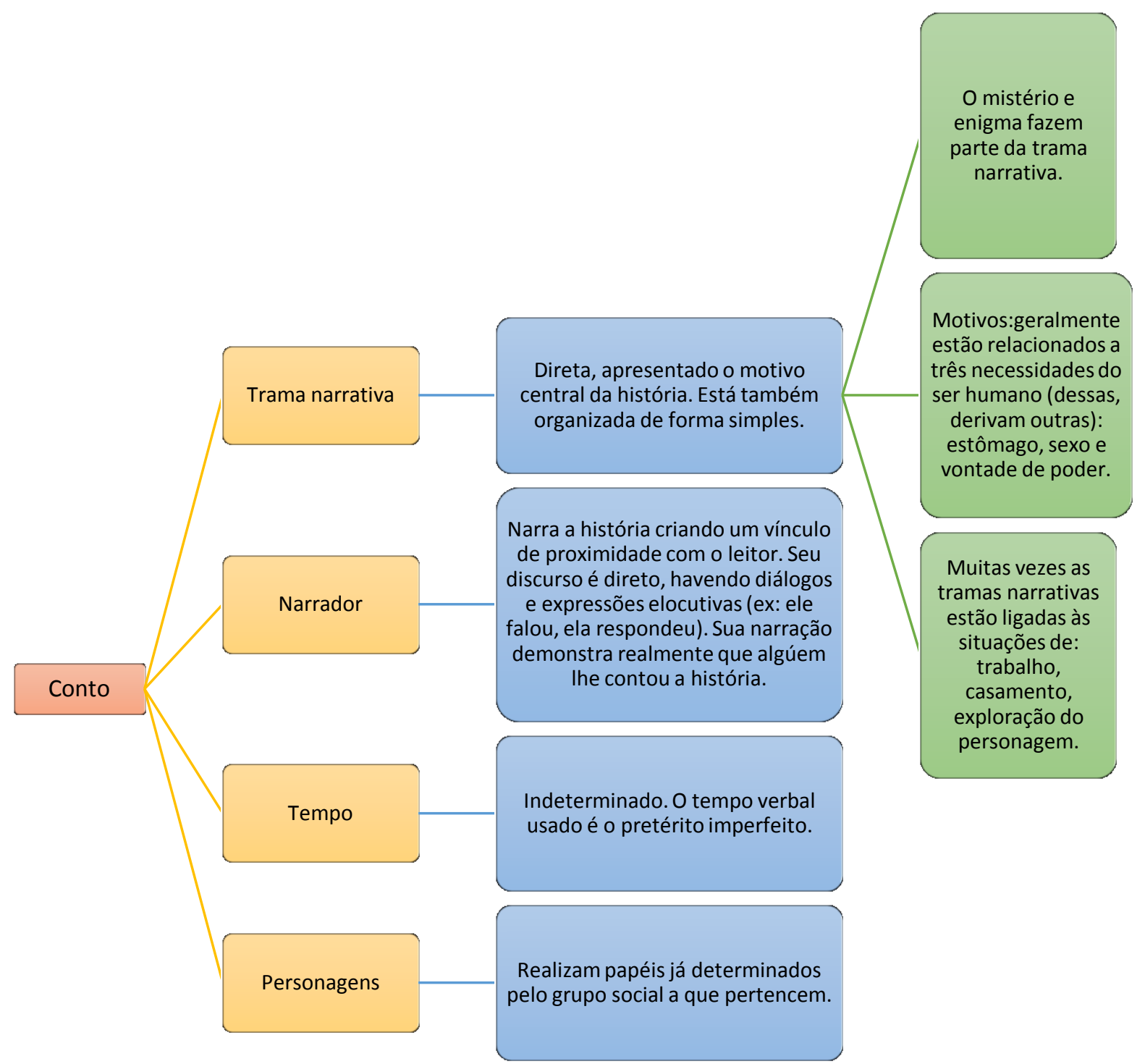

Fonte: Elaborado pelo autor

Com base no quadro-resumo apresentado acima, podemos diferenciar, de acordo com Coelho (1987), o conto de fadas do conto maravilhoso da seguinte maneira: os contos de fadas, originários da cultura celta, tratam de problemas relacionados a questões existenciais dos personagens e suas histórias têm como base um obstáculo a ser superado. Dessa forma, “[...] o herói alcança sua auto-realização existencial, seja pelo encontro de seu verdadeiro eu, seja pelo encontro da princesa, que encarna o ideal a ser alcançado" (COELHO, 1987, p. 13). 
A presença de fadas não é um requisito necessário, entretanto, no universo que envolve a efabulação ${ }^{5}$, está inserido o contexto da magia feérica ${ }^{6}$. Já nos contos maravilhosos, a autora esclarece que o problema central está relacionado a uma problemática social que envolve o herói. Em outras palavras, “[...] trata-se sempre do desejo de auto-realização do herói (ou antiherói) no âmbito socioeconômico, através de conquista de bens, riquezas, poder material. [...] Geralmente, a miséria ou a necessidade de sobrevivência física é ponto de partida para as aventuras da busca" (COELHO, 1987, p. 14). A efabulação não traz uma magia feérica, apesar do cotidiano ser mágico. Nesse caso, envolve animais que falam, objetos mágicos, gênios, etc. Esses contos têm origem oriental, as narrativas de As mil e uma noite reúnem um acervo significativo deles. Coelho (2003, p. 79, grifo da autora) elucida que a junção das problemáticas existencial e social dá origem aos contos exemplares, "[...] Câmara Cascudo chama-os de contos de encantamento, de que são exemplos: Chapeuzinho Vermelho, $O$ Pequeno Polegar, João e Maria.”

A sereiazinha é um conto de fadas, pois toda a narrativa está centrada em questões existenciais da personagem principal. No quadro abaixo, esmiuçamos as invariantes básicas desse conto, assim como fez Coelho (2000), apresentando também suas possíveis variantes correspondentes:

Quadro 1: Invariantes e variantes da estrutura do conto A sereiazinha.

\begin{tabular}{|c|l|}
\hline \multicolumn{1}{|c|}{ INVARIANTES } & \multicolumn{1}{c|}{ VARIANTES } \\
\hline 1. Desígnio & $\begin{array}{l}\text { Desejo de ter a imortalidade da alma, ter o amor do } \\
\text { príncipe e casar-se com ele. }\end{array}$ \\
\hline 2. Viagem & $\begin{array}{l}\text { A primeira viagem foi feita ao ir à superfície para } \\
\text { conhecer um pouco sobre o mundo dos humanos; sua } \\
\text { segunda viagem foi a ida à morada da bruxa e a } \\
\text { terceira viagem foi morar com o príncipe. }\end{array}$ \\
\hline 3. Desafio ou Obstáculo & $\begin{array}{l}\text { Ser uma sereia a impossibilitava de estar junto dos } \\
\text { humanos e viver e sentir como eles. }\end{array}$ \\
\hline 4. Mediação natural & $\begin{array}{l}\text { O poder mágico consiste em ser a poção mágica feita } \\
\text { pela bruxa, que lhe traria pernas ou invés de nadadeira, } \\
\text { porém, ao pisar no chão, a personagem estaria como } \\
\text { que pisando em facas afiadas. Nisso perdeu sua voz, } \\
\text { entregando à bruxa sua língua. }\end{array}$ \\
\hline 5. Conquista do objetivo & $\begin{array}{l}\text { Toma da forma humana, porém não se casa com o } \\
\text { príncipe, pois ele desposa outra mulher. Tendo que }\end{array}$ \\
\hline
\end{tabular}

\footnotetext{
${ }^{5}$ Segundo Coelho (2000, p. 66) efabulação seria "a trama da ação ou dos acontecimentos, sequência dos fatos, peripécias, sucessos, situações".

${ }^{6}$ De acordo com Coelho (1987, p. 13), "essas narrativas trazem os argumentos desenvolvidos dentro da magia feérica - reis, rainhas, príncipes, princesas, fadas, gênios, bruxas, gigantes, anões, objetos mágicos, metamorfoses, tempo e espaço fora da realidade conhecida, etc".
} 


\begin{tabular}{|l|l|}
\hline & $\begin{array}{l}\text { escolher entre sua vida ou a vida do jovem rapaz, } \\
\text { prefere morrer por amor. Entretanto, como recompensa } \\
\text { por seu sofrimento e boas ações, conquista a } \\
\text { imortalidade da alma. }\end{array}$ \\
\hline
\end{tabular}

Fonte: elaborado pelo autor.

Dessa teoria apresentada, interessa-nos fazer a análise das narrativas do conto $A$ sereiazinha observando e seguindo quatro categorias: enredo, narrador, personagem principal e cenário.

\section{COMPARANDO AS DIFERENÇAS E AS SEMELHANÇAS}

Os livros usados para análise das narrativas do conto $A$ sereiazinha foram: o texto original, Histórias Maravilhosas de Andersen (1995); primeira adaptação, A pequena sereia (2010); segunda adaptação, A Pequena Sereia (2014); terceira adaptação, A Pequena Sereia (2016?).

Quadro 2: Os livros analisados.

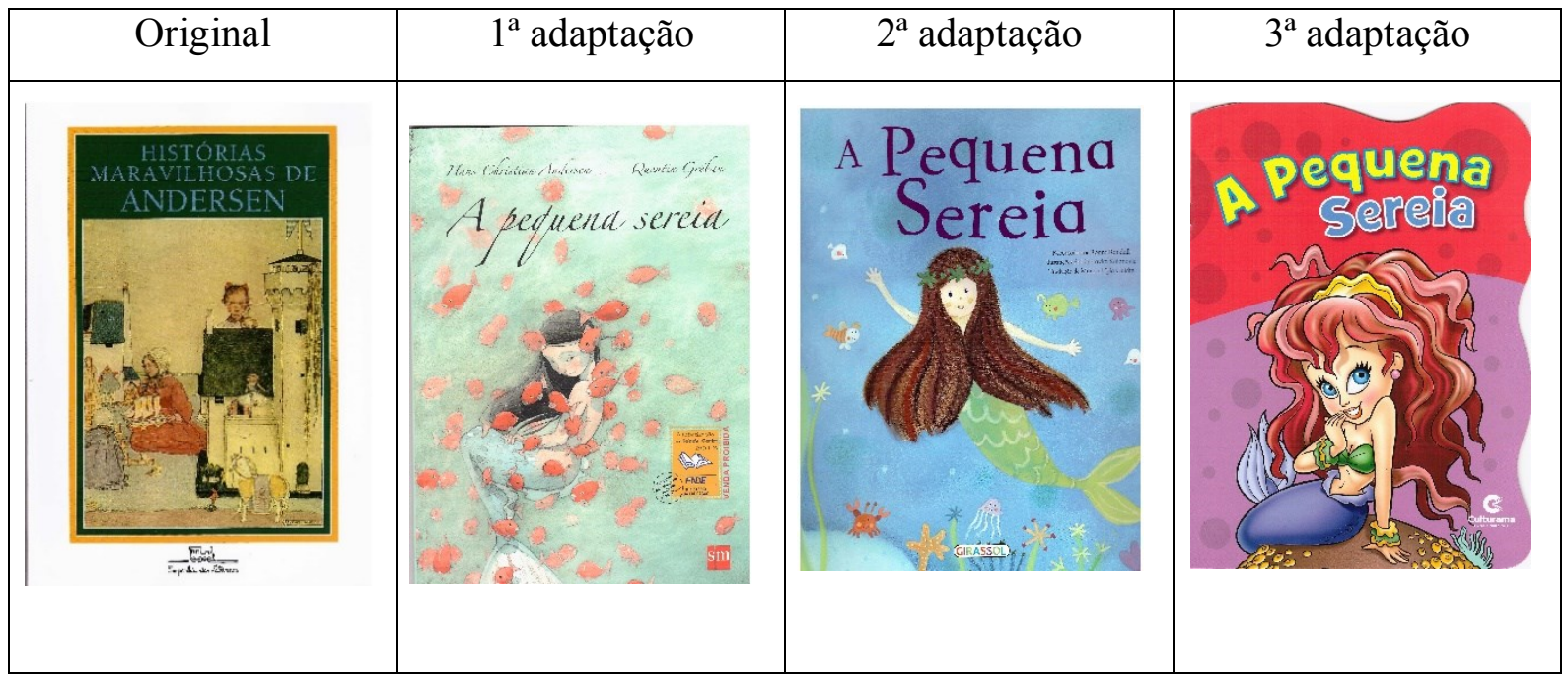

Fonte: Elaborado pelo autor.

\section{O enredo}

O enredo de um conto maravilhoso ou conto de fadas, segundo Propp (2001, p. 51) está centrado no:

[...] desenvolvimento narrativo que, partindo de um dano ou uma carência e passando por funções intermediárias, termina com o casamento ou outras funções utilizadas como desenlace. A função final pode ser a recompensa, obtenção do objeto procurado ou, de modo geral, a recuperação do dano, o salvamento da perseguição etc. 
Andersen mostra essa compilação coerente em seu texto, que as sucessões de acontecimentos que vão surgindo ao longo da narrativa são devidas às inquietações causadas por uma personagem que não está satisfeita com o que ela é, há uma “[...] ânsia de expansão do Eu, pela necessidade de conhecimento de novos horizontes e da aceitação do seu Eu pelo outro" (COELHO, 2003, p. 25). Ser diferente das outras sereias é o que a faz se apaixonar pelo príncipe. Uma das perguntas que podemos retirar da história é: por que as outras irmãs da sereiazinha não se apaixonam pelos humanos ou querem viver na mesma situação que eles? Andersen toca na questão da individualidade, e, logo no início da narrativa, ele descreve a sereiazinha sendo diferente das demais. O único elo comum que existe entre as irmãs é a vontade de ir à superfície, mas, quando isso acontece, logo depois elas perdem o interesse, preferindo sempre estar junto dos seus; ao contrário da sereiazinha.

Coelho (2000) elucida que Andersen traz para suas narrativas o pensamento cristão, em que predomina a virtude, os bons atos sendo sempre recompensados, o bem sempre se sobressaindo. A sereiazinha está dentro desse contexto de ações cristãs que transmite uma mensagem positiva. Ela não se casa com o príncipe, entretanto ela conquista algo maior: a imortalidade da alma, que era uma de suas inquietações.

O quadro abaixo resume as alterações feitas no enredo das adaptações; o que supostamente predominou e o que de essencial foi retirado. São elementos importantes que tornariam esse conto num conto de fadas, dentro da estrutura morfológica criada por Propp (2001).

Quadro 3: Enredo

\begin{tabular}{|c|c|c|c|}
\hline Enredo & $1^{\mathrm{a}}$ adaptação & $2^{\mathrm{a}}$ adaptação & $3^{\mathrm{a}}$ adaptação \\
\hline $\begin{array}{l}\text { Modificação } \\
\text { da história }\end{array}$ & $\begin{array}{l}\text {-Ação da personagem } \\
\text { principal está } \\
\text { vinculada apenas em } \\
\text { conseguir o amor do } \\
\text { príncipe. } \\
\text {-O príncipe é } \\
\text { retratado de forma } \\
\text { leviana, pois se } \\
\text { interessa } \\
\text { sereiazinha, mas casa- } \\
\text { se com outra sem } \\
\text { haver justificativa } \\
\text { para isso; } \\
\text { - A sereiazinha morre } \\
\text { e não conquista a } \\
\text { imortalidade da alma. }\end{array}$ & $\begin{array}{l}\text {-Tanto a ilustração } \\
\text { quanto o texto retratam } \\
\text { uma personagem feliz; } \\
\text {-A sereiazinha canta } \\
\text { para o príncipe quando } \\
\text { o resgata ao invés de } \\
\text { beijá-lo; } \\
\text { - O príncipe acorda e vê } \\
\text { de relance } \\
\text { sereiazinha; } \\
\text { - As irmãs aconselham } \\
\text { a sereiazinha a ir } \\
\text { procurar a bruxa; } \\
\text {-Ao tomar a forma } \\
\text { humana, aparece } \\
\text { vestida usando sapatos }\end{array}$ & $\begin{array}{l}\text {-Tanto a ilustração } \\
\text { quanto o texto retratam } \\
\text { uma personagem feliz; } \\
\text {-O príncipe sabe que } \\
\text { quem o salvou do } \\
\text { naufrágio fora uma } \\
\text { sereia; } \\
\text {-A bruxa é chamada de } \\
\text { feiticeira; } \\
\text {-As irmãs da sereiazinha } \\
\text { convencem a bruxa a lhe } \\
\text { devolver sua voz; } \\
\text {-O príncipe reconhece a } \\
\text { sereiazinha em forma } \\
\text { humana pela voz; } \\
\text {-O príncipe casa-se com }\end{array}$ \\
\hline
\end{tabular}




\begin{tabular}{|c|c|c|c|}
\hline & & $\begin{array}{l}\text { prateados ao invés de } \\
\text { nua; } \\
\text {-Imediatamente, } \\
\text { príncipe reconhece a } \\
\text { sereiazinha ao vê-la; } \\
\text {-O príncipe a pede em } \\
\text { casamento e, quando a } \\
\text { beija, esta recupera sua } \\
\text { voz; } \\
\text {-Casaram-se e a } \\
\text { sereiazinha ganha um } \\
\text { nome: Marina. }\end{array}$ & a sereiazinha. \\
\hline $\begin{array}{ll}\text { O que foi } \\
\text { retirado do } \\
\text { enredo }\end{array}$ & $\begin{array}{l}\text {-Não há a avó da } \\
\text { sereiazinha, } \\
\text { personagem que lhe } \\
\text { conta sobre a } \\
\text { imortalidade da alma; } \\
\text {-A moça que encontra } \\
\text { o príncipe após o } \\
\text { naufrágio naro } \\
\text { aparece; nã pela } \\
\text {-A busca a alma } \\
\text { imortalidade da } \\
\text { não é abordada. }\end{array}$ & $\begin{array}{l}\text { - Ausência da avó. } \\
\text {-O conflito existencial } \\
\text { da personagem } \\
\text { principal; } \\
\text {-O sofrimento causado } \\
\text { por suas escolhas; } \\
\text {-A conquista da } \\
\text { imortalidade da alma; } \\
\text {-O suicídio da } \\
\text { personagem principal, } \\
\text { que escolhe morrer a } \\
\text { matar seu grande amor. }\end{array}$ & $\begin{array}{l}\text {-O conflito existencial da } \\
\text { personagem principal; } \\
\text {-O sofrimento causado } \\
\text { por suas escolhas; } \\
\text {-A conquista da } \\
\text { imortalidade da alma; } \\
\text {-O suicídio da } \\
\text { personagem principal, } \\
\text { que escolhe morrer a } \\
\text { matar seu grande amor. }\end{array}$ \\
\hline $\begin{array}{l}\text { O que se } \\
\text { conservou } \\
\text { da história } \\
\text { original }\end{array}$ & $\begin{array}{l}\text {-O desejo de todas as } \\
\text { sereias de subirem à } \\
\text { superfície; } \\
\text {-O envolvimento da } \\
\text { personagem principal } \\
\text { com o príncipe; } \\
\text {-As viagens à } \\
\text { superfície, à morada } \\
\text { da bruxa, ao palácio } \\
\text { do príncipe; } \\
\text {-A poção feita pela } \\
\text { bruxa; } \\
\text {-O acordo feito pelas } \\
\text { irmãs da sereiazinha } \\
\text { com a bruxa; } \\
\text {-A escolha de morrer } \\
\text { a ter que matar o } \\
\text { príncipe. }\end{array}$ & $\begin{array}{l}\text {-A ida à superfície; } \\
\text {-O naufrágio; } \\
\text {-A moça que encontra o } \\
\text { príncipe na área após o } \\
\text { naufrágio; } \\
\text {-A ida da sereiazinha à } \\
\text { morada da bruxa; } \\
\text {-O amor da sereiazinha } \\
\text { pelo príncipe. }\end{array}$ & $\begin{array}{l}\text {-A avó que narra as } \\
\text { histórias sobre a vida dos } \\
\text { humanos; } \\
\text {-O naufrágio; } \\
\text {-Uma das irmãs sabia } \\
\text { onde o príncipe morava. } \\
\text {-O amor da sereiazinha } \\
\text { pelo príncipe. }\end{array}$ \\
\hline
\end{tabular}

Fonte: elaborado pelo autor.

O que acontece nas adaptações é uma anulação do pensamento cristão. O principal objetivo da sereiazinha não é conquistado, pois ela não quer apenas ter a forma humana, ela quer ser humana e o que diferencia isso é a imortalidade da alma. A primeira adaptação 
apenas centraliza a dor, a ingenuidade e o perdão da personagem principal, não há uma ênfase nos problemas existenciais dessa personagem. Tanto a sereiazinha quanto o príncipe são tomados por atitudes levianas: o príncipe demonstra o seu amor, mas não quer desposá-la e casa-se com outra, o que não acontece no original, pois ele se encanta pela sereiazinha, mas seu amor, que na verdade é uma gratidão, é pela moça que ele supostamente acha que o salvou do naufrágio. A gratidão também faz parte do pensamento cristão. É uma forma de amor diferente também abordada na história original. A segunda e terceira adaptações modificam o final da história, logo o que interessa é a relação amorosa entre os dois jovens, sendo, nada mais justo, dar um final feliz aos personagens. Nenhuma relação com o pensamento cristão, criado por Andersen, aparece na história; o conto torna-se superficial porque não se aprofunda em justificar e explicar as ações dos personagens.

A segunda adaptação traz um problema na construção da narrativa, pois aparece uma personagem que encontra o príncipe na praia após o naufrágio, entretanto a narrativa não explica quem de fato é essa personagem e a retira da história sem dar um esclarecimento ao leitor. A primeira e a terceira adaptações não mencionam a personagem que acha o príncipe na praia, do que inferimos que é justamente para não refletir o pensamento cristão, pois é ela quem casa com o príncipe, e os textos adaptados parecem não querer se aprofundar nesse dilema criado por Andersen. Concluímos que as adaptações não justificam as ações dos personagens, pois discutir sobre essas ações é discutir sobre o caráter humano e a individualidade de cada um.

\section{O narrador}

De acordo com Coelho (2000) e citado em nosso esquema, o narrador, nesse tipo de estrutura narrativa, tem característica de um contador de histórias, que faz uma mediação entre o teor narrado e o leitor. Assim, entende-se que essas narrativas vieram da comunicação oral, por isso, esse recurso narrativo serve para atrair a atenção imediata dos leitores. Segundo a autora, "o narrador pertence ao texto; fora deste, ele não existe. Entidade fictícia, o narrador é responsável pela enunciação ou pela dinâmica que concretiza a narrativa, isto é, que produz o discurso narrativo.” (COELHO, 2000, p. 67). Já o foco narrativo, trata-se de “[...] um dos fatores estruturantes mais importantes do processo narrativo. Como se sabe, o foco narrativo indica o olhar através do qual são vistos todos os incidentes do que é narrado" (COELHO, 2000, p. 68-69). 
Com base na teoria de Coelho (2000), criamos um quadro comparativo que expõe o tipo de narrador e foco narrativo no conto A sereiazinha:

Quadro 4: Narrador

\begin{tabular}{|c|c|c|c|}
\hline Texto & Narrador & Foco narrativo & Trechos \\
\hline $\begin{array}{l}\text { Texto } \\
\text { original }\end{array}$ & $\begin{array}{lr}\text { Dialógico } & - \text { ele } \\
\text { reconhece } & \text { a } \\
\text { existência } & \text { do } \\
\text { leitor e se dirige } \\
\text { a ele. }\end{array}$ & \begin{tabular}{lr} 
Foco de & \multicolumn{2}{c}{ consciência } \\
narrativa total - \\
Conhece não apenas \\
as & \multicolumn{2}{c}{ intenções, } \\
sentimentos & e \\
pensamentos & da \\
personagem principal \\
como das demais \\
personagens.
\end{tabular} & $\begin{array}{l}\text { [...] a mais moça das seis ainda ia } \\
\text { ter que esperar cinco anos } \\
\text { inteirinhos até receber permissão } \\
\text { para subir do fundo do mar e ver } \\
\text { que cara tinha o nosso mundo. } \\
\text { (p. 67) } \\
\text { Ah, vocês precisam ver a irmã } \\
\text { mais moça ouvindo essas } \\
\text { novidades! (p. 67) } \\
\text { A sereiazinha foi criando } \\
\text { carinho pelos seres humanos, } \\
\text { sentia um desejo infinito de } \\
\text { poder andar e ir para junto deles. } \\
\text { (p. 77) }\end{array}$ \\
\hline $\begin{array}{l}1^{\mathrm{a}} \\
\text { adaptação }\end{array}$ & Onisciente & 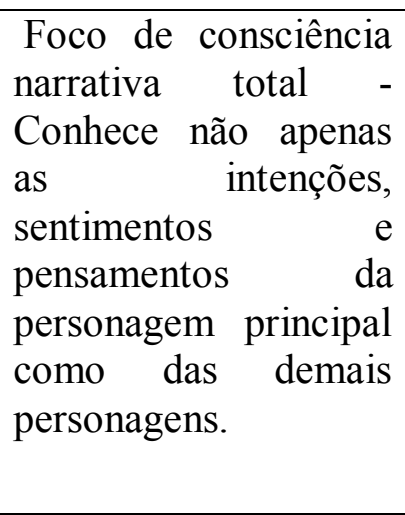 & $\begin{array}{l}\text { A pequena sereia suspirou } \\
\text { observou com desespero sua } \\
\text { cauda. (p. 14) } \\
\text { Dia após dia, o príncipe gostava } \\
\text { cada vez mais da pequena sereia, } \\
\text { embora não demonstrasse a } \\
\text { intenção de desposá-la. (p. } 24 \text { ) } \\
\text { A pequena sereia sentiu o } \\
\text { coração se quebrar. (p. 24) }\end{array}$ \\
\hline $\begin{array}{l}2^{\mathrm{a}} \\
\text { adaptação }\end{array}$ & Onisciente & $\begin{array}{l}\text { Foco de consciência } \\
\text { parcial - sabe sobre os } \\
\text { pensamentos e } \\
\text { sentimentos da } \\
\text { personagem principal. }\end{array}$ & $\begin{array}{l}\text { A pequena sereia viu tudo } \\
\text { afundar e desejou muito que o } \\
\text { príncipe estivesse a salvo. (n/p) } \\
\text { "Preciso salvá-lo", pensou ela. } \\
(\mathrm{n} / \mathrm{p}) \text {. }\end{array}$ \\
\hline $\begin{array}{l}3^{\mathrm{a}} \\
\text { adaptação }\end{array}$ & Onisciente & $\begin{array}{l}\text { Foco de consciência } \\
\text { parcial - sabe sobre os } \\
\text { pensamentos e } \\
\text { sentimentos da } \\
\text { personagem principal. }\end{array}$ & $\begin{array}{l}\text { O príncipe a achou parecida com } \\
\text { a sereiazinha que salvara sua } \\
\text { vida e se encantou por ela. Pena } \\
\text { que ela não pudesse falar, pois } \\
\text { então, o príncipe a reconheceria } \\
\text { pela bela voz. (p. } 14-15 \text { ) }\end{array}$ \\
\hline
\end{tabular}

Fonte: elaborado pelo autor.

O texto narrativo de um conto de fadas ou de um conto maravilhoso tem toda uma herança de sentidos ocultos inseridos, que são imprescindíveis à vida do homem; vale retomar Coelho (1987) sobre isso. São narrativas que fazem referências às verdades humanas cheias 
de significado. A segunda e terceira adaptação fogem de uma efabulação construída de provas pelas quais a personagem principal precisa passar, para que ela consiga alcançar a sua autorrealização existencial (COELHO, 1987). O texto original, por outro lado, aproxima o leitor e o conquista com afirmações intercaladas na narrativa que lhe permitem diferenciar os dois mundos - o real do fantástico. "Por que não vão imaginar que lá no fundo do mar só tem areia branca! Não, no fundo do mar crescem árvores e plantas fantásticas." (ANDERSEN, p. 62, grifo nosso).

As histórias de Andersen, como afirma Coelho (2003), expõem os problemas da sociedade na qual viveu, mas tentam num tom romântico anular as injustiças mostrando a fé religiosa. "Como bom cristão, Andersen sugere a piedade e a resignação, para que o céu seja alcançado na eternidade”. (COELHO, 2003, p. 25). Esse tom romântico em suas histórias oferece ao público infantil um novo padrão de comportamento a ser adotado na nova sociedade que estava se formando (COELHO, 2003). O que inferimos acerca disso é que nenhum valor ideológico é passado na segunda e na terceira adaptações. Ao não passarem valor ideológico, resulta apenas o estereótipo da narração de uma história mundialmente conhecida.

\section{Personagem principal}

Dividimos a descrição da personagem principal em descrição física e psicológica:

Quadro 5: Personagem principal

\begin{tabular}{|c|c|c|}
\hline Texto & Descrição física & Descrição psicológica \\
\hline $\begin{array}{l}\text { Texto } \\
\text { original }\end{array}$ & $\begin{array}{l}\text { Sua pele era perfeita e suave } \\
\text { como uma pétala de rosa, os } \\
\text { olhos eram azuis como o mar } \\
\text { mais profundo, mas como as } \\
\text { irmãs, ela não tinha pés, pois } \\
\text { seu corpo acabava numa cauda } \\
\text { de peixe. (p. 62) }\end{array}$ & $\begin{array}{l}\text { Ela era uma criança estranha, quieta e } \\
\text { pensativa. (p. 64) } \\
\text { A maior alegria da princesinha mais moça } \\
\text { era ouvir histórias sobre o mundo humano } \\
\text { lá de cima. (p. 66) } \\
\text { A sereia beijou sua testa e acariciou o } \\
\text { cabelo molhado. Para ela, o príncipe era } \\
\text { igual à estátua de mármore de seu } \\
\text { jardinzinho lá do fundo do mar. } \\
\text { Desejando com todas as suas forças que } \\
\text { ele não morresse, ela lhe deu outro beijo. } \\
\text { (p.74) }\end{array}$ \\
\hline $\begin{array}{l}1^{\mathrm{a}} \\
\text { adaptação }\end{array}$ & $\begin{array}{l}\text { As princesinhas eram } \\
\text { encantadoras. A caçula, porém, } \\
\text { era de todas a mais bela. Tinha a }\end{array}$ & $\begin{array}{l}\text { Dali por diante, ela, que sempre fora } \\
\text { silenciosa e pensativa, fechou-se ainda } \\
\text { mais. (p. 14) }\end{array}$ \\
\hline
\end{tabular}




\begin{tabular}{|c|c|c|}
\hline & $\begin{array}{l}\text { pele fina e transparente como } \\
\text { branca pétala de rosa e, feito as } \\
\text { irmãs, da cintura para baixo, em } \\
\text { vez de pernas, exibia uma longa } \\
\text { cauda de peixe. (p. } 6 \text { ) }\end{array}$ & $\begin{array}{l}\text { Ela então se inclinou e deu um beijo na } \\
\text { testa do jovem. Em sua mão a faca } \\
\text { tremeu. Num arroubo, ela a jogou para } \\
\text { longe, no meio das ondas. Contemplou o } \\
\text { príncipe uma última vez e mergulhou no } \\
\text { mar, onde sentiu o corpo dissolver-se na } \\
\text { espuma. (p. 28) }\end{array}$ \\
\hline $\begin{array}{l}2^{\mathrm{a}} \\
\text { adaptação }\end{array}$ & $\begin{array}{l}\text { Era uma vez uma pequena e } \\
\text { doce sereia que vivia nas } \\
\text { profundezas do oceano. Tinha } \\
\text { olhos azuis da cor do mar e uma } \\
\text { linda cauda cintilante. }(\mathrm{n} / \mathrm{p}) \text {. }\end{array}$ & Não tem. \\
\hline $\begin{array}{l}3^{\mathrm{a}} \\
\text { adaptação }\end{array}$ & $\begin{array}{l}\text { A sereiazinha tinha os olhos } \\
\text { azuis, uma pele clarinha e uma } \\
\text { voz suave de encantar o mundo. } \\
\text { (p. 2) }\end{array}$ & $\begin{array}{l}\text { Era tímida, e só ficava feliz quando ouvia } \\
\text { histórias do mundo dos homens. (p. 3) } \\
\text { Ao retornar para casa, contou tudo para as } \\
\text { suas irmãs e disse que queria ser uma } \\
\text { mulher de verdade para casar com o } \\
\text { príncipe. (p. 11) }\end{array}$ \\
\hline
\end{tabular}

Fonte: elaborado pelo autor.

Para Gomes (1991, p. 82): "nos contos de fada, a ação é mais importante que os detalhes da personalidade das personagens. Elas são descritas em traços reduzidos, o necessário para situá-las na ação”. Propp (2001) ratifica a explicação de Gomes, elucidando que é na própria ação desenvolvida pela personagem que se evidenciarão todos os seus traços comportamentais. Andersen anuncia sutilmente as atitudes tomadas pela personagem principal que dão início ao advento da carência em sua vida e a necessidade extrema de ser aceita pelo outro, o que a motiva a tomar a atitude de ir à procura da bruxa do mar. Notamos que há uma preocupação da segunda e terceira adaptações em fazer apenas uma descrição física da sereiazinha sem levar em consideração que o psicológico estaria implícito nas atitudes da personagem. A primeira adaptação busca ser diferente, pois apresenta os dois elementos, conduzindo a história com mais coerência.

\section{Cenário}

De acordo com Coelho (2000), as narrativas primordiais, cuja importância está centralizada nas ações dos personagens, não focalizam em descrever significativamente o ambiente em que se passam as histórias, "[...] servindo apenas como ponto de apoio à existência das personagens e dos fatos" (CEOLHO 2000, p. 107). Entretanto, a autora também argumenta que determinadas ações tornam-se funcionais devido à localização em que se passam, pois esta "intervém na sequência dos acontecimentos ou cria a atmosfera propícia à 
sequência dramática. Veja-se a influência do clima frio de rigoroso inverno que provoca a situação problemática em O homem e a Serpente” (COELHO, 2000, p. 108, grifo da autora).

Escolhemos analisar o cenário do conto $A$ sereiazinha, pois vimos que as ações da personagem principal acontecem pela necessidade de mudança tanto do Eu quanto do ambiente no qual ela se encontra. Andersen descreve dois mundos - dos mares e dos humanos - que mostram duas condições diferentes de vida, cada um com suas vantagens e desvantagens.

Dessa forma verificaremos na obra original e nas adaptadas se há algum detalhamento sobre esses dois mundos:

Quadro 6: Cenário

\begin{tabular}{|c|c|c|c|c|}
\hline Texto & $\begin{array}{c}\text { Mais } \\
\text { detalhado }\end{array}$ & $\begin{array}{c}\text { Pouco } \\
\text { detalhado }\end{array}$ & $\begin{array}{c}\text { Sem } \\
\text { detalhamento }\end{array}$ & Trechos \\
\hline $\begin{array}{l}\text { Texto } \\
\text { original }\end{array}$ & $X$ & & & $\begin{array}{l}\text {-As paredes do palácio do rei do mar } \\
\text { são coral e as longas janelas pontudas } \\
\text { são de âmbar muito transparente. O } \\
\text { telhado, no entanto, é feito de ostras } \\
\text { que se abrem e se fecham com o } \\
\text { movimento da água. (p. 62) } \\
\text {-O palácio era de uma pedra lustrosa, } \\
\text { amarelo-clara, e tinha grandes } \\
\text { escadarias de mármore, uma das quais } \\
\text { descia até o mar. No alto do telhado } \\
\text { erguiam-se cúpulas douradas; todo ele } \\
\text { era cercado por colunas entre as quais } \\
\text { se viam estátuas de mármore tão } \\
\text { perfeitas que pareciam que iam sair } \\
\text { andando. Pelo cristal das altas janelas } \\
\text { viam-se salões magníficos; nas paredes } \\
\text { e janelas havia cortinados e tapeçarias } \\
\text { das mais finas seda e todas as paredes } \\
\text { eram decoradas com grandes pinturas } \\
\text { que eram um verdadeiro primor. (p. } \\
76 \text { ) }\end{array}$ \\
\hline $\begin{array}{l}1^{\mathrm{a}} \\
\text { adaptação }\end{array}$ & & $\mathrm{X}$ & & $\begin{array}{l}\text {-Nas profundezas do mar, onde a água } \\
\text { é azul e transparente como o cristal } \\
\text { mais puro, eleva-se o castelo do Rei do } \\
\text { Mar. (p. 6) } \\
\text { Não descreve o palácio do príncipe e a } \\
\text { única nota que há é: '[...] na volta, } \\
\text { traziam milhares de notícias sobre as } \\
\text { cidades e seus ruídos, os navios, as } \\
\text { florestas, as pessoas (p. } 8 \text { ) }\end{array}$ \\
\hline
\end{tabular}




\begin{tabular}{|l|l|l|l|l|}
\hline $\begin{array}{l}\text { adaptação } \\
2^{\mathrm{a}}\end{array}$ & & $\mathrm{X}$ & Sem descrição \\
\hline $\begin{array}{l}3^{\mathrm{a}} \\
\text { adaptação }\end{array}$ & & & $\mathrm{X}$ & Sem descrição \\
\hline
\end{tabular}

Fonte: elaborado pelo autor.

A curiosidade em saber sobre a vida que os humanos levavam e como eram os lugares em que eles habitavam também compõe a personalidade da personagem principal. Andersen descreve as riquezas dos dois mundos de forma que essa descrição colaborará com a sequência dramática da história. Ele descreve também a curiosidade das irmãs da sereiazinha pelo mundo dos humanos, narra o que cada uma encontrou, mas deixa claro que todas estavam satisfeitas com o mundo em que pertenciam. Assim, os lugares descritos pelo autor são importantes porque ajudam a dar coerência à história. A primeira adaptação não se preocupa com a descrição do cenário, apenas com as ações dos personagens, entretanto, há uma falha na construção da história, pois quando a sereiazinha toma da poção mágica, ela já se vê no palácio do príncipe. Dessa forma, entendemos que a poção mágica deu a forma humana à sereia mais a localização do castelo do príncipe, só que isso não é dito pela bruxa, que fez a poção, diferente do original em que as irmãs mostram onde se localiza a morada do rapaz. Na terceira adaptação, é citado que as irmãs sabiam dessa localização, mas nada se fala sobre os dois mundos. No conto de fadas existe, portanto, o mediador mágico, mas nem tudo é resolvido com mágica, é necessário dar detalhes para que essa história, especificamente, tenha uma sequência lógica para os acontecimentos.

\section{CONCLUSÃO}

Bettelheim (2007) denuncia que as versões simplificadas feitas sobre os contos de fadas limitam o sentido real que compõe essas narrativas primordiais, que estariam vinculadas ao comportamento humano e às interações sociais. Esta pesquisa corrobora com as afirmações feitas pelo autor. Realmente o texto original proporciona uma compreensão mais crítica e reflexiva da história. Andersen entrega uma narração construída com detalhes que são importantes, justamente, buscando a coerência no desmembramento do enredo. Com isso, as preocupações do autor em descrever os aspectos comportamentais da sereiazinha contribuem para o entendimento das ações tomadas por ela no desenrolar da trama. As relações de causa e consequência são bem desenvolvidas na trama criada pelo autor. $O$ simples fato de a 
personagem se sentir atraída pelo mundo dos humanos não surge de imediato, é algo alimentado e misturado às suas angústias.

As adaptações, ao contrário, se restringem a narrar a relação amorosa entre os dois personagens e ignoram o pensamento cristão, marca das narrativas de Andersen, sem construir um enredo que sustende com coerência a trama. Ambiguidades surgem ao longo das narrativas, o sentimento do príncipe pela sereiazinha deixa em dúvida o seu caráter. Duas adaptações fogem do final triste, mas esperançoso, e se restringem apenas ao "viveram felizes para sempre", descaracterizando o conto original e recriando uma nova história. A superficialidade nessas adaptações, como Bettelheim (2007) afirma, não contribui para o amadurecimento da criança no sentido de que ela se identifique com os personagens e muito menos oferece experiências que possam desenvolver o seu caráter.

\section{REFERÊNCIAS}

ANDERSEN, Hans. Christian. Histórias maravilhosas de Andersen. São Paulo: Companhia das Letrinhas, 1995.

Paulo: Edições SM, 2010.

A pequena sereia. Adaptação de MOLHANT, Muriel. São

BETTELHEIM, Bruno. A psicanálise dos contos de fadas. 21. ed. São Paulo: Paz e Terra, 2007.

BRASIL. Ministério da Educação. Secretaria da Educação Básica. Parâmetros Curriculares Nacionais: língua portuguesa. 3. ed. Brasília, DF: MEC/SEB, 2000.

COELHO, Nelly Novaes. O conto de fadas. São Paulo: Ática, 1987.

Literatura infantil: teoria, análise, didática. São Paulo: Moderna, 2000.

O conto de fadas: símbolos, mitos e arquétipos. São Paulo: DCL, 2003.

COLEÇÃO CONTOS CLÁSSICOS. A pequena sereia. Caxias do Sul, RS: Culturama, [2016?].

GOMES, Heidi Strecker. Análise de texto: teoria e prática. São Paulo: Editora Atual, 1991.

LAJOLO, Marisa; ZILBERMAN, Regina. Literatura infantil brasileira: história e histórias. 6. ed. São Paulo: Ática, 2007.

PROPP. Vladimir I. Morfologia do Conto Maravilhoso. São Paulo: Copymarket.com, 2001.

RANDALL, Ronne. A pequena Sereia. São Paulo: Girassol, 2014. Não paginado. 
O AUTOR

Diogo Fernando dos Santos é mestrando em Linguística Aplicada pela Universidade de Taubaté. Especialista em Gramática e Uso pela Universidade de Taubaté e Alfabetização: relação entre ensino e aprendizagem pelo Instituto Vera Cruz.

E-mail: diogof.santos@globo.com 